\title{
Collagen phagocytosis by lung alveolar macrophages in animal models of emphysema
}

\author{
M. Lucattelli*, E. Cavarra*, M.M. de Santi\#, T.D. Tetley ", P.A. Martorana*, G. Lungarella*
}

Collagen phagocytosis by lung alveolar macrophages in animal models of emphysema. M. Lucattelli, E. Cavarra, M.M. de Santi, T.D. Tetley, P.A. Martorana, G. Lungarella. (C) ERS Journals Ltd 2003.

ABSTRACT: Under steady state conditions the intracellular pathway is the major route of collagen catabolism in tissues characterised by rapid collagen turnover. In the lung, the collagen is subject to continuous remodelling and turnover however, the intracellular pathway of collagen degradation is unusual under physiological conditions.

The current authors previously described crystalloid inclusions in alveolar macrophages of mice with genetic emphysema at the time of septal disruption. Using an immunogold technique these inclusions were identified as collagen-derived products and related to intracytoplasmic collagen degradation. To examine whether a different degree of protease burden in lung interstitium may influence the route of intracellular collagen degradation, collagen phagocytosis by alveolar macrophages was studied in various mouse models of emphysema at the time when emphysema develops.

Evident collagen by-products in alveolar macrophages were observed in destructive processes characterising spontaneous models of emphysema either with negligible (blotchy mouse) or moderate (pallid mouse) elastase burden. On the other hand, intracellular collagen by-products were appreciated only in a few macrophages from tight-skin mice with high elastolytic burden and could not be observed in mice with a very severe burden after elastase instillation. In conclusion, the interstitial level of proteases burden can affect the way by which the collagen is cleared (intracellularly versus extracellularly).

Eur Respir J 2003; 22: 728-734.
*Dept of Physiopathology and Experimental Medicine, and ${ }^{\#}$ Institute of Pathological Anatomy, University of Siena, Siena, Italy, National Heart and Lung Institute, Imperial College School of Medicine, London, UK.

Correspondence: G. Lungarella, Dept Physiopathology and Experimental Medicine, University of Siena, Via Aldo Moro N. 6, 53100 Siena, Italy.

Fax: 390577234019

E-mail: lungarella@unisi.it

Keywords: Alveolar macrophages, animal models of emphysema, crystalloid inclusions, fibrillar collagens, intracellular collagen byproducts, protease burden

Received: April 302003

Accepted after revision: June 282003

This work was supported by a grant from Ministero dell'Istruzione, Università e Ricerca Scientifica (MIUR; Rome, Italy) and by a grant from University of Siena (PAR, Progetti).
Collagenous proteins are major constituents of all extracellular matrices. Several types of collagen are recognised on the basis of variations in the structure of their polypeptide chains. Types I, II, III, V and XI collagens form fibrils and are hence known as fibrillar collagens [1].

A collagen network composed largely of type I and III fibrillar collagens is found in the extracellular space of the lung alveolar walls, skin, myocardium, uterus and several other tissues. It plays a dominant role in maintaining the tissue architecture and chamber geometry. Given its tensile strength, fibrillar collagen is a major determinant of tissue stiffness [1].

Under physiological conditions, synthesis and degradation of collagen is balanced to maintain tissue homeostasis [2, 3]. In lung tissue, disrupted homeostasis leads to an imbalance between synthesis and degradation, resulting in either collagen destruction (i.e. emphysema) or excessive collagen deposition (i.e. fibrosis) $[4,5]$.

There are two important pathways for collagen degradation $[6,7]$. The extracellular pathway involves matrix metalloproteinases that are capable of degrading $\geqslant 1$ types of collagen, while the intracellular route involves lysosomal degradation of fibrils internalised by cells such as macrophages, fibroblasts and osteoclasts. The mechanisms that regulate collagen phagocytosis in vivo are poorly defined although it is widely accepted that under steady state conditions the intracellular pathway is the major route of collagen catabolism in several tissues and organs characterised by rapid collagen turnover (periodontal ligament, gingiva, periosteum, uterus during postpartum involution, etc.) [8]. In this context, and especially in soft connective tissues, fibroblasts appear to play a major role both in extracellular and in intracellular collagen degradation [8].

In the lung, the collagen is subject to continuous remodelling and turnover [3] however, the intracellular pathway of collagen degradation is not seen under physiological conditions.

The current authors recently reported a relevant collagen phagocytosis by lung macrophages during the ongoing destructive process that characterises the onset of spontaneous emphysema in pallid mice with $\alpha_{1}$-proteinase inhibitor deficiency [9]. In these animals, the present authors demonstrated the presence of intracytoplasmic crystalloid inclusions similar to those observed in macrophages from connective tissue undergoing rapid remodelling [10,11], whose nature was for a long time an object of debate [12]. Using electron microscopy and an immunogold-labelling technique, these inclusions were identified by the present authors as collagen-derived products and have been related to the intracellular route of collagen degradation that takes place during septal disruption.

Although knowledge of the role and mechanisms of the intracellular pathway of collagen digestion by macrophages has increased considerably during the past years [13, 14], many details of the processes involved still remain to be elucidated. Actually, in vivo studies are still lacking in this area. When investigating this field, questions such as which factors initiate or modulate collagen phagocytosis may be of 
importance in understanding the pathophysiology of interstitial lung diseases, such as emphysema and fibrosis.

In a recent study [15] it has been clearly demonstrated that macrophages can adhere to denatured but not to native type I and III collagens. This has been ascribed to specific surface receptors (macrophages scavenger receptors (MSRs)) that bind fibril-forming collagens which have been denatured. It is well known that during acute and chronic lung injury, extracellular matrix proteins are exposed to an environment laden with proteolytic enzymes and/or oxidants, which can degrade and/or alter their native conformation [16].

To examine whether the degree of protease burden in lung interstitium influences the route of intracellular collagen degradation, the current authors studied collagen phagocytosis by alveolar macrophages in various mouse models of emphysema at the time when emphysema develops. The mouse strains selected for this study develop spontaneous lung lesions in presence of negligible, moderate or high interstitial protease burden. The occurrence of intracytoplasmic crystalloid inclusions in alveolar macrophages was also studied in a mouse model of experimental emphysema in which a very severe interstitial protease burden is obtained via intratracheal instillation of human neutrophil elastase.

\section{Materials and methods}

\section{Animals}

Mice of the strain $\mathrm{C} 57 \mathrm{Bl} / 6 \mathrm{~J}$ (C57), and its mutants pallid C57 Bl/6J pa/pa and tight-skin C57 Bl/6J Tsk/pa mice were from the current authors' colony. Blotchy $\mathrm{C} 3 \mathrm{H} \mathrm{Blo} /+$ mice were from the Department of Comparative Biology, Charing Cross and Westminster Medical School (London, UK). The mice were housed in groups of two to four in macrolon cages. Room temperature was kept at $22-24^{\circ} \mathrm{C}$; relative humidity at 40-50\%; food and water were supplied ad libitum.

The Local Ethical Committee of the University of Siena approved all animal experimentation.

\section{Experimental protocol}

Mice of various strains (tight-skin, blotchy, and pallid) known to develop spontaneous emphysema were used at the time of septal disruption. Thus, tight-skin mice were 1-2 months old [17], blotchy mice 3-6 months old [18] and pallid mice 8-12 months old [19]. In an additional study, emphysema was induced in C57 mice known not to develop this lesion spontaneously. In particular, 2 month-old C57 mice received intratracheally, under light anaesthesia $25 \mu \mathrm{g}$ of elastase from human sputum (Elastin Products, Co., Owensville, Missouri, USA) dissolved in $50 \mu \mathrm{L}$ saline. These animals were used at 14-21 days after elastase instillation. The animal models that were used and the time of development of emphysematous lesions are entered in table 1.
At the selected time points, mice were anaesthetised with sodium pentobarbital and were killed by severing the abdominal aorta. After thoracotomy, the thoracic viscera were immediately removed. The lungs were washed in cold saline and then handled for morphological studies. Alternatively, they were used for bronchoalveolar lavage (BAL) determinations.

\section{Morphological examination of pulmonary macrophages from lung sections}

For morphological investigation, lung samples were fixed in $2 \%$ glutaraldehyde in $0.1 \mathrm{M}$ sodium cacodylate buffer, $\mathrm{pH} 7.2$ for $2 \mathrm{~h}$ at $4{ }^{\circ} \mathrm{C}$, postfixed in $1 \%$ buffered osmium tetraoxide $\left(\mathrm{OsO}_{4}\right)$, dehydrated and embedded in epoxy resin (Araldite). Small cubes $\left(1 \mathrm{~mm}^{3}\right)$ of lung tissue taken at several levels from lungs of the various strains of mice were processed in a similar way. Lung semithin sections $(0.5-1 \mu \mathrm{m}$ thick) were cut on a LKB Ultratome V and stained with $1 \%$ toluidine blue. Ultrathin ( $600 \AA)$ sections from lung specimens were mounted on copper grids, stained with uranyl acetate-lead citrate and examined in a Philips 300 electron microscope.

\section{Determination of elastase burden by immuno-electron microscopy}

The immunogold method (postembedding technique) was used to localise elastase in thin lung sections prepared for electron microscopy using antimouse leukocyte elastase (antiMLE) antibodies as previously described in detail [20]. Briefly, lung tissue blocks (five per animal) taken from five tight-skin, five blotchy and five pallid mice were used. The density of gold particles per square micrometer of lung tissue was determined for each of the micrographs with a superimposed quadratic lattice grid. A total of 50 micrographs were thus analysed for each animal, and the average gold particle density of lung connective tissue for the two groups was calculated.

The elastolytic burden was scored as negligible $(-:<2$ gold particles per $\left.\mu \mathrm{m}^{2}\right)$, moderate $\left(+: 2-8\right.$ gold particles per $\left.\mu \mathrm{m}^{2}\right)$ and marked $\left(++:>8\right.$ gold particles per $\left.\mu \mathrm{m}^{2}\right)$. The elastolytic burden of the $\mathrm{C} 57 \mathrm{~B} 1 / 6 \mathrm{~J}$ mice could not be determined since these mice were injected with human neutrophil elastase that does not react with anti-MLE antibodies. However, the amount of human neutrophil elastase injected intratracheally allows the elastolytic burden in these mice to be considered "very severe".

\section{Immunolocalisation of collagen in alveolar macrophages}

Some tissue samples, handled in a similar way as reported above to localise elastase, were used to investigate the nature of crystalloid inclusion observed in the different animal

Table 1.-Schematic overview of the development of emphysema in different mouse models

\begin{tabular}{lccc}
\hline Mouse strains & Emphysema & Development of lesions & [Ref no.] \\
\hline Blotchy & Spontaneous & $4-6$ months after birth & {$[18]$} \\
Pallid & Spontaneous & $8-12$ months after birth & {$[19,20]$} \\
Tight-skin & Spontaneous & $1-2$ months after birth & [17, 19] \\
C57 B1/6J & Induced (i.tr. instillation & $14-21$ days after instillation & \\
& $25 \mu$ gelastase) & & \\
\hline
\end{tabular}

i.tr.: intratracheal. 
groups. Collagen by-products in pulmonary macrophages were localised by an immunogold method using rabbit antimouse collagen I immunoglobulin $(\mathrm{Ig}) \mathrm{G}$ or rabbit antimouse collagen III IgG, as previously reported [9].

\section{Bronchoalveolar lavage and biochemical analysis}

After sacrificing animals, the trachea was isolated and then cannulated with a 20 gauge blunt needle. By the aid of a peristaltic pump (P-1 Pharmacia, Uppsala, Sweden) the lungs were repeteadly lavaged three times with $0.6 \mathrm{~mL}$ normal saline. The average recovery was $95 \%$. The lavage fluid was then centrifuged to remove cells and supernatants were assayed for hydroxyproline concentration [22] and lactic dehydrogenase (LDH) [23] activity. Enzyme activity was reported in international units (IU) which are equal to micromoles of substrate converted per minute.

\section{Statistical analysis}

For each parameter either measured or calculated, the values of the individual animals were averaged and the SD was calculated. The significance of the differences was calculated using one way analysis of variance (F-test). A p-value of $<0.05$ was considered significant.

\section{Results}

The animal models used in this study, and the different time of development of emphysematous lesions are entered in table 1 .

Intracytoplasmic crystalloid inclusions were found in alveolar macrophages of the three strains of mice which spontaneously develop emphysema: blotchy (fig. 1a), tight-skin (fig. 1b) and pallid (fig. 1c, 1d). These structures were morphological similar in all strains. In particular, at high magnification (fig. 2a) the inclusions had a "needle-like" appearance, were electron dense and were bounded by a single membrane. In general, macrophages containing inclusions were endowed with an active membrane, as evinced by the presence of fine pseudopodia and an irregular outline. In some alveoli, the crystalloid "needles" appeared as free structures associated with cellular debris.

Additionally, as previously reported for the pallid mouse, the inclusions observed in the blotchy and tight-skin mice showed a positive reaction for collagen type I (fig. 2 b) as well as for collagen type III (fig. 2c), by using an immunogoldlabelling technique.

Contrary to these findings observed in strains that spontaneously develop emphysema, the crystalloid inclusions were never seen in alveolar macrophages from C57 Bl/6J (C57) mice from 2-16 months of age (fig. 1e) [9]. Similarly, no inclusions were found in macrophages from 2 month-old C57
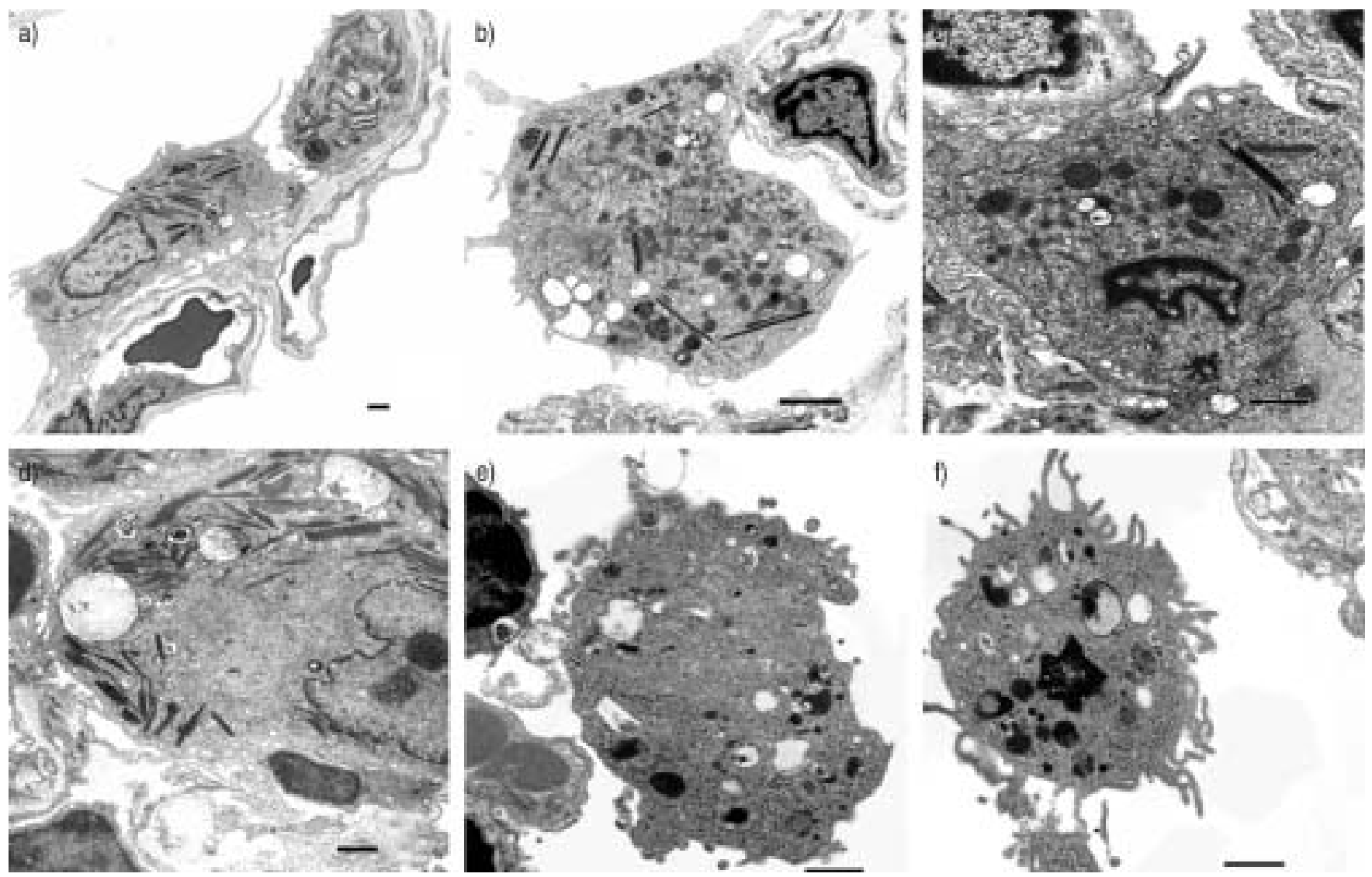

Fig. 1. -a) Electron micrograph of an alveolar septum of a 5 month-old blotchy mouse showing an alveolar macrophage containing crystalloid inclusions. Details of these inclusions are shown in fig. 2a. b) Electron micrograph of an alveolar macrophage from a 1 month-old tight-skin mouse. Some crystalloid inclusions are present in the cytoplasm. c) Alveolar macrophage from an 8 month-old pallid mouse containing some crystalloid inclusions bound by a single membrane. d) Alveolar macrophage from a 12 month-old pallid mouse. Several crystalloid inclusions are evident. e) Alveolar macrophage from a 12 month-old C57 B1/6J mouse. No crystalloid inclusions can be seen. f) Alveolar macrophage from an elastase-treated C57 B1/6J mouse. The cytoplasm is free from crystalloid inclusions. Sections were stained with uranyl acetate and lead citrate. Scale bar $=1 \mu \mathrm{m}$. 

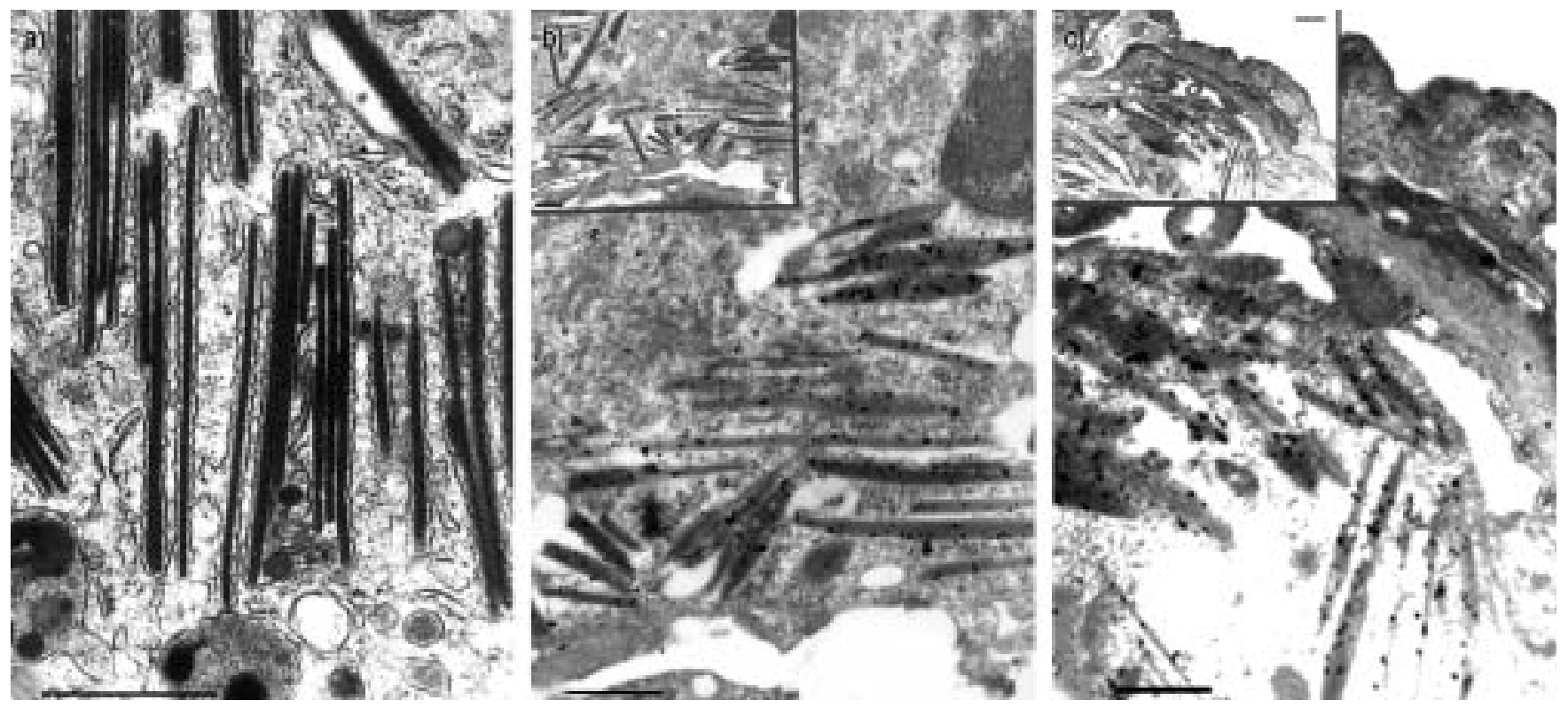

Fig. 2. - a) Detail of fig. 1a showing crystalloid inclusions bound by a single membrane. b) Alveolar macrophage from a 5 month-old blotchy mouse showing a positive reaction for collagen type I antibody on the crystalloid inclusions. Inset shows a lower magnification of these structures. c) Alveolar macrophage from a 5 month-old blotchy mouse showing a positive reaction for collagen type III antibody on the crystalloid inclusions. Inset shows a lower magnification of these structures. Sections were stained with uranyl acetate and lead citrate. Scale bar $=2 \mu \mathrm{m}$.

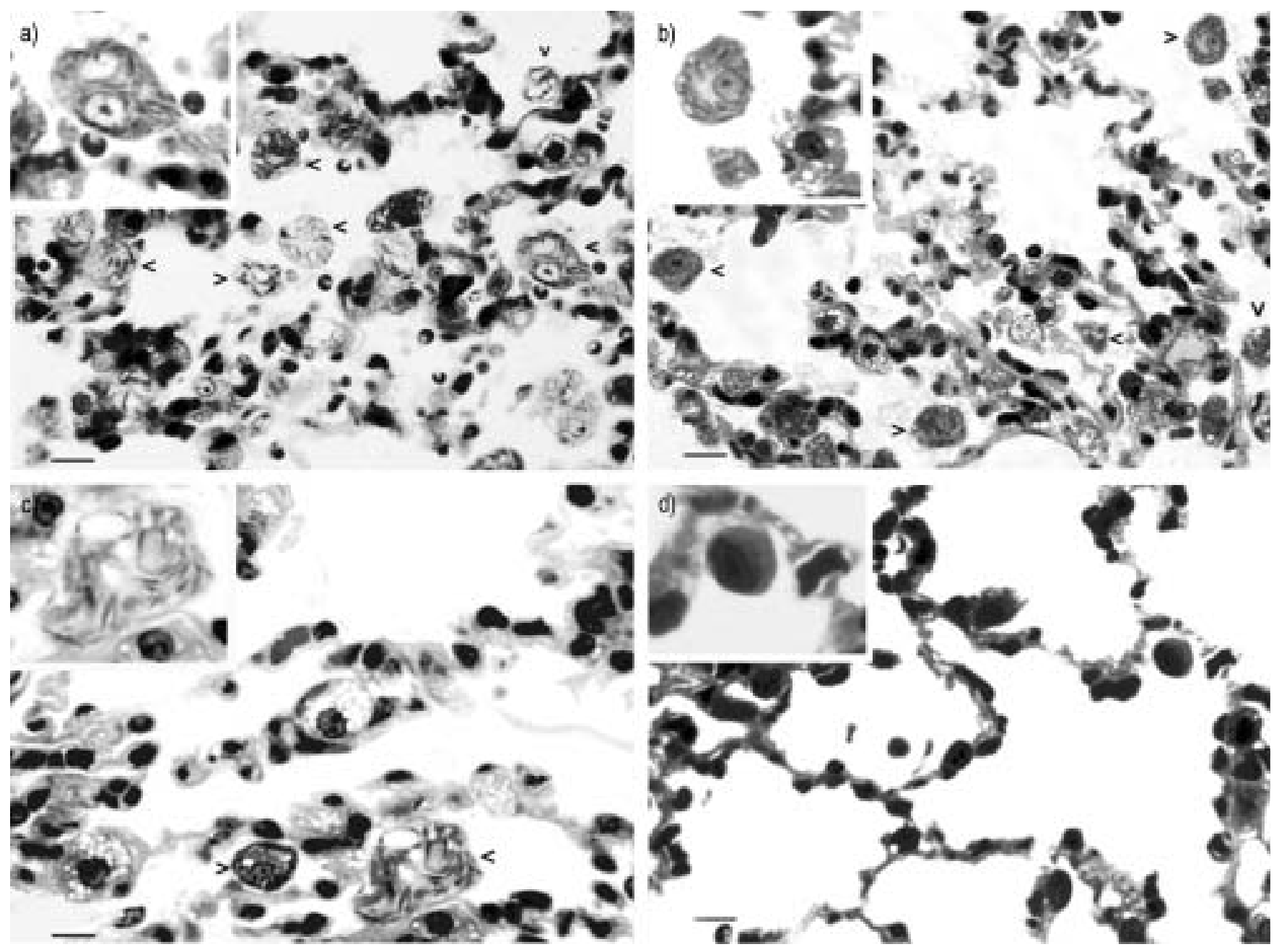

Fig. 3.-Semithin sections stained with toluidine blue from lungs of a) blotchy, b) pallid, c) tight-skin and d) elastase-treated C57 mice. Arrowheads indicate alveolar macrophages containing dark thin bodies. Insets show a higher magnification of these macrophages. Scale bar $=7.8 \mu \mathrm{m}$. 
Table 2. - Elastolytic burden and distribution of macrophages with inclusions in different animal models of emphysema

\begin{tabular}{lcc}
\hline Mouse strains & $\begin{array}{c}\text { \% of macrophages } \\
\text { with inclusions }\end{array}$ & $\begin{array}{c}\text { Elastolytic burden } \\
\text { (gold particles per } \mu \mathrm{m}^{2} \text { ) }\end{array}$ \\
\hline Blotchy & $10-20$ & $<2$ \\
Pallid & $35-85$ & $2-8$ \\
Tight-skin & $1-3$ & $>8$ \\
C57 B1/6J & 0 & Very severe $^{\#}$ \\
$\quad$ after elastase & &
\end{tabular}

\#: elastolytic burden of the $\mathrm{C} 57 \mathrm{~B} 1 / 6 \mathrm{~J}$ mice could not be determined since these mice were injected with human neutrophil elastase that does not react with mouse neutrophil elastase antibodies. However, the amount of human neutrophil elastase injected intratracheally $(25 \mu \mathrm{g})$ allows the elastolytic burden to be considered "very severe".

in which emphysema was induced by intratracheal instillation of elastase (fig. 1f).

The crystalloid inclusions could also be seen at light microscopy, in plastic sections stained with toluidine blue as dark thin bodies engulfing the cytoplasm of pulmonary macrophages from blotchy, pallid and tight-skin mice (fig. 3a-c). These features were never observed in the cytoplasm of macrophages from C57 mice treated with elastase (fig. 3d).

The percentage of macrophages exhibiting "needle-like" inclusions is presented in table 2 . The pallid mice had the highest percentages of macrophages with inclusions (35-85\%). At 12 months of age the vast majority of pallid macrophages (up to $85 \%$ of the total cell population) were completely filled with crystalloids. The blotchy mouse showed $10-20 \%$ of macrophages with inclusions, while the tight-skin mouse showed such changes only in very few macrophages $(1-3 \%)$.

The values of the elastolytic burden (reported as gold particles density) detected in animals developing spontaneous emphysema are also entered in the table 2 . The mean values of particles was $4.9 \pm 1.2$ per $\mu \mathrm{m}^{2}$ in pallid mice and $9.6 \pm 1.6$ per $\mu \mathrm{m}^{2}$ in tight-skin mice $(\mathrm{p}<0.05)$. These values are related to pallid mice of 8 months of age and tight-skin mice of 1 month of age, i.e. at the time when these mice developed emphysema and crystalloid inclusions first appeared. The level of gold particle density found within the alveolar wall of congenic C57 BL76J at the various ages (1-12 months) was not greater than the background levels detected on control lung sections incubated without primary antibody $(0.7 \pm 0.8$ per $\mu \mathrm{m}^{2}$ ).

Of interest, after elastase instillation no macrophages with inclusions could be detected in C57 mice in which the elastolytic burden could be assumed as "very severe". In pallid mice with a lower elastolytic burden than tight-skin mice, a greater percentage of macrophages with crystalloid inclusions were detected than in the tight-skin mice. In blotchy mice in which the cause of emphysema cannot be the result of an elastolytic process, the origin of the intracytoplasmic crystalloid inclusions is probably related to the destruction of alveolar septa due to the connective tissue abnormalities of this mutant.

As mentioned above, the crystalloid inclusions begin to appear in macrophages of animals with spontaneous emphysema at the time in which the septal destruction takes place. In particular, they appeared in 8 month-old pallid and 4 month-old blotchy mice when a significant increase in LDH activities ( +36 and $41 \%$, respectively) in respect to average control values $\left(94.11\right.$ and $86.43 \mathrm{IU} \cdot \mathrm{L}^{-1}$ ) was observed in BAL fluids. At these times, detectable amounts of hydroxyproline were found in (BAL) fluids from pallid $\left(0.170 \pm 0.015 \mu \mathrm{g} \cdot \mathrm{mL}^{-1}\right)$ and from blotchy $\left(0.190 \pm 0.026 \mu \mathrm{g} \cdot \mathrm{mL}^{-1}\right)$ mice.

Of interest, the increase of the percentage of macrophages with the "needle-like" inclusions observed in pallid mice

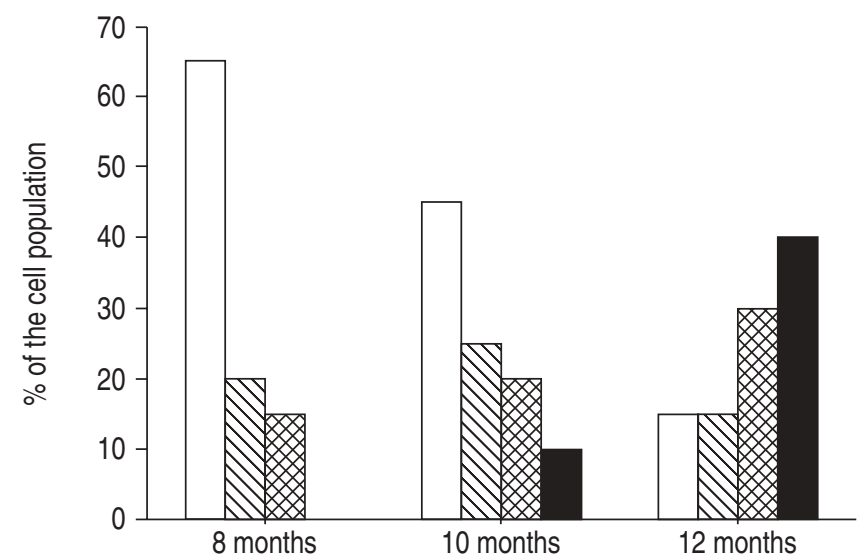

Fig. 4.-Percentage distribution of pallid macrophages containing different amounts of crystalloids at various time points. Macrophages have been scored according to the number of inclusions present in the cytoplasm ( $\square: 0 ; \mathbb{\mathbb { Q }}:<10 ; \mathbf{B}: 10-40 ; \mathbf{\square}:>40)$.

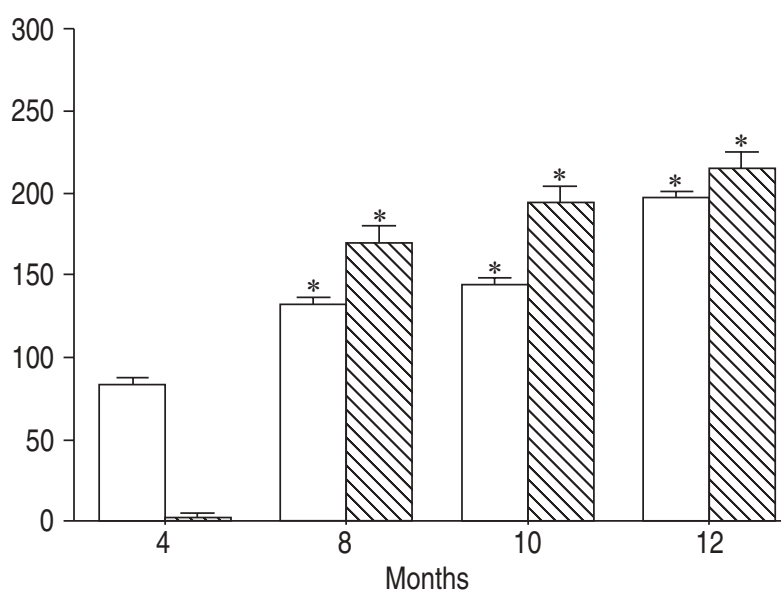

Fig. 5. - Lactic dehydrogenase activity $\left(\square\right.$; IU $\left.\cdot \mathrm{L}^{-1}\right)$ and hydroxyproline $\left(\mathbb{\nabla} ; \mathrm{ng} \cdot \mathrm{mL}^{-1}\right)$ in bronchoalveolar lavage fluids from pallid mice at various ages. Values are the mean \pm SD of eight animals in each group. *: $\mathrm{p}<0.05$ versus 4 month-old mice.

between 8 and 12 months of age, was accompanied by a progressive increase in the number of crystalloid inclusions within the cells (fig. 4). The latter figure paralleled the increase of LDH activity and hydroxyproline content in BAL fluids (fig. 5).

\section{Discussion}

The current paper reports an evident collagen phagocytosis by alveolar macrophages in the ongoing destructive processes that characterise two spontaneous models of emphysema with negligible (blotchy) or moderate (pallid) elastase burden. On the other hand, intracellular collagen degradation was appreciated only in very few macrophages from tight-skin mice with a marked elastolytic burden and could not be observed in C57 mice in which an intratracheal elastase instillation results in a very severe protease burden.

The data presented suggest that the interstitial levels of protease burden can influence the way in which collagen is cleared. It is widely accepted that extracellular matrix (ECM) proteins, including type I and III collagens, are attacked by a variety of proteases, which acting alone or together, either 
completely digest the proteins or alter their native conformation [24-26]. Under the different conditions of septal injury reported by the current authors, the local ECM proteins are exposed to various amounts of proteolytic enzymes that can degrade their molecules differently.

Elastolytic enzymes, and in particular elastases, are able to cleave interstitial collagens [24, 27]. They can also promote collagen catabolism by modifying the protease-antiprotease balance in the interstitial environment either activating several metalloproteases with collagenolytic activity [28] or binding and/or digesting common inhibitors (i.e. $\alpha_{2}$-macroglobulin, tissue inhibitors of metalloproteases) [29].

The ability of macrophages to differentially adhere via MSRs to proteolytically modified collagen type I and III has been recently demonstrated [15]. This may represent an important factor in initiating collagen phagocytosis by macrophages, and may offer an explanation why the intracellular route of collagen degradation is not usual in the lung under physiological conditions.

The data obtained also support the idea that collagen phagocytosis by macrophages participates in the removal of injured extracellular matrix during the development of a slow progressive emphysema such as that occurring in pallid and blotchy mice. In fact, the crystalloid inclusions appeared only when a significant increase in LDH activity and detectable amounts of hydroxyproline could be demonstrated in BAL fluids. The progressive increase of the percentage of macrophages with crystalloid inclusions and of the number of these inclusions within the cells that were observed in pallid mice during the exacerbation of the ongoing destructive process (from 8 months of age onward) represent an additional support for such a view.

Of interest, in the aforementioned models of emphysema characterised by high protease burden (i.e. tight-skin and C57 mice after elastase treatment) the alveolar destruction is followed by an enhanced collagen synthesis. This results in marked deposition of collagen fibrils in the residual septa [30-33].

It has been proposed that lung synthesis of collagen and elastin can be controlled by the state of the extracellular matrix and peptides made soluble by elastase. Actually, there is evidence in vitro $[34,35]$ and in vivo [36] that products of collagen and elastin degradation by elastase may have a role in the deposition of these interstitial proteins. In the present authors' opinion the different routes of collagen degradation, the levels of protease burden and thereby the differences in cleavage and removal of collagen molecules may affect the remodelling of the interstitial matrix after an alveolar injury. The current authors are actively pursuing this hypothesis.

In summary, the present study provides evidence that different interstitial levels of protease burden in emphysema may be associated with different routes of collagen clearance (intracellular versus extracellular). Additionally, it may form the basis for future investigations regarding the remodelling of the interstitial matrix in emphysema.

\section{References}

1. Chambers RC, Laurent GJ. Collagens. In: Crystal RG, West JB, Weibel ER, Barnes PJ, eds. The Lung. Philadelphia, Lippincott-Raven, 1997; pp. 709-727.

2. Laurent GJ. Dynamic state of collagen degradation in vivo and their possible role in regulation of collagen mass. $A$ J Physiol 1987; 252: C1-C9.

3. McAnulty RJ, Laurent GJ. Collagen synthesis and degradation in vivo. Evidence for rapid rates of collagen turnover with extensive degradation of newly synthesised collagen in tissue of the adult rat. Collagen Rel Res 1987; 7: 93-104.
4. Laurent GJ. Lung collagen: more than scaffolding. Thorax 1986; 41: 418-428.

5. O'Donnell MD, O'Connor CM, FitzGerald MX, Lungarella G, Cavarra E, Martorana PA. Ultrastructure of lung elastin and collagen in mouse models of spontaneous emphysema. Matrix Biol 1999; 18: 357-360.

6. Everts V, Beertsen W, Schroder R. Effects of the proteinase inhibitors leupeptin and E-64 on osteoclastic bone resorption. Calcif Tissue Int 1988; 43: 172-178.

7. Sodek J, Overall C. Matrix degradation in hard and soft connective tissues. In: Davidovitch Z, ed. The Biological Mechanisms of Tooth Eruption and Root Resorption. Birmingham, AL, EBSCO Media, 1988; pp. 303-311.

8. Everts V, van Der Zee E, Creemers L, Beertsen W. Phagocytosis and intracellular digestion of collagen, its role in turnover and remodelling. Histochem $J$ 1996; 28: 229245.

9. De Santi MM, Martorana PA, Cavarra E, Lungarella G. Pallid mice with genetic emphysema. Neutrophil elastase burden and elastin loss occur without alteration in the bronchoalveolar lavage cell population. Lab Invest 1995; 73: $1-8$.

10. Parakkal PF. Involvement of macrophages in collagen resorption. J Cell Biol 1969; 41: 345-354.

11. Parakkal PF. Macrophages: the time course and sequence of their distribution in the postpartum uterum. $J$ Ultrastruct Res 1972; 40: 284-291.

12. Ghadially FN. Cytoplasmic matrix and its inclusions. In: Ghadially FN, ed. Ultrastructural Pathology of the Cell and Matrix. London, Butterworths, 1988; pp. 953-1041.

13. Deporter DA. Collagen phagocytosis by stimulated mouse peritoneal macrophages in vitro. J Periodont Res 1979; 14 : 323-331.

14. Van Der Zee E, Everts V, Hoeben K, Beertsen W. Cytokines modulate phagocytosis and intracellular digestion of collagen fibrils in rabbit periosteal explants. Inverse effects on procollagenase production and collagen phagocytosis. J Cell Sci 1995; 108: 3307-3315.

15. Gowen BB, Borg TK, Ghaffar A, Mayer EP. Selective adhesion of macrophages to denatured forms of type I collagen is mediated by scavenger receptors. Matrix Biol 2000; 19: 61-71.

16. Weiss SJ. Tissue destruction by neutrophils. $N$ Engl J Med 1989; 320: 365-376.

17. Martorana PA, van Even P, Gardi C, Lungarella G. A 16month study of the development of genetic emphysema in tight-skin mice. Am Rev Respir Dis 1989; 39: 226-232.

18. Fisk DE, Kuhn C. Emphysema-like changes in the lungs of the blotchy mouse. Am Rev Respir Dis 1976; 113: 787-797.

19. Keil M, Lungarella G, Cavarra E, van Even P, Martorana PA. A scanning electron microscopic investigation of genetic emphysema in tight-skin, pallid, and beige mice, three different C57B1/6J mutants. Lab Invest 1996; 74: 353362.

20. Martorana PA, Brand T, Gardi C, et al. The pallid mouse. A model of genetic $\alpha_{1}$-antitrypsin deficiency. Lab Invest 1993; 68: $233-241$

21. Valentine R, Rucker RB, Chrisp CE, Fisher GR. Morphological and biochemical features of elastase-induced emphysema in strain A/J mice. Toxicol Appl Pharmacol 1983; 68: $451-461$.

22. Kivirikko KI, Laitinen O, Prockop DJ. Modification of a specific assay for hydroxyproline in urine. Anal Biochem 1967; 19: 249-255.

23. Bergmeyer HU, Bernt E. Lactate dehydrogenase UV assay with pyruvate and NADH. In: Bergmeyer HU, ed. Methods of Enzymatic Analysis. New York, Academic Press, 1974; pp. $574-579$.

24. Barrett AJ. Leukocyte elastase. Method Enzymol 1981; 80: 581-588.

25. Murphy G, Reynolds JJ. Extracellular matrix degradation. In: Royce PM, Steinmann B, eds. Connective Tissue and its 
Heritable Disorders. New York, Wiley-Liss, 1993; pp. 287316.

26. Quigley JP, Berkenpas MB, Aimes RT, Chen JM. Serino protease and metalloprotease cascade system involved in pericellular proteolysis. Cell Differ Develop 1990; 32: 263-276.

27. Gadek JE, Fells GA, Wright DG, Crystal RG. Human neutrophil elastase functions as type III collagen "collagenase". Biochem Biophys Res Commun 1980; 95: 1815-1822.

28. McElvaney NG, Crystal RG. Proteases in lung injury. In: Crystal RG, West JB, Weibel ER, Barnes PJ, eds. The Lung. Philadelphia, Lippincott-Raven, 1997; pp. 2205-2218.

29. McElvaney NG, Crystal RG. Antiproteases and lung defense. In: Crystal RG, West JB, Weibel ER, Barnes PJ, eds. The Lung. Philadelphia, Lippincott-Raven, 1997; pp. 2219-2235.

30. Kuhn C, Yu SY, Chraplyvy M, Linder HE, Senior RM. The induction of emphysema with elastase. II. Changes in connective tissue. Lab Invest 1976; 34: 372-380.

31. Yu SY, Keller NR. Synthesis of lung collagen in hamsters with elastase-induced emphysema. Exp Mol Pathol 1978; 29 $37-43$.

32. Fonzi L, Lungarella G. Correlation between biochemical and morphological repair in rabbit lungs after elastase injury. Lung 1980; 158: 165-171

33. Gardi C, Martorana PA, Calzoni P, et al. Lung collagen syntesis and deposition in tight-skin mice with genetic emphysema. Exp Mol Pathol 1992; 56: 163-172.

34. Foster JA, Rich CB, Miller MF. Pulmonary fibroblasts: an in vitro model of emphysema: regulation of elastin gene expression. J Biol Chem 1990; 265: 15544-15549.

35. Gardi C, Calzoni P, Marcolongo P, Cavarra E, Vanni L, Lungarella $G$. Collagen breakdown products and lung collagen metabolism: an in vitro study on fibroblast cultures. Thorax 1994; 49: 312-318.

36. Gardi C, Pacini A, de Santi MM, et al. Development of interstitial lung fibrosis by long-term treatment with collagen breakdown products in rabbits. Res Commun Chem Pathol Pharmacol 1990; 68: 235-250. 